\title{
Multitrophic Interactions in the Sea: Assessing the Effect of Infochemical-Mediated Foraging in a 1-d Spatial Model
}

\author{
N. D. Lewis ${ }^{1,2}$ *, A. Morozov ${ }^{3}$, M. N. Breckels ${ }^{1}$, M. Steinke${ }^{1}$, E. A. Codling ${ }^{1,2}$ \\ ${ }^{1}$ School of Biological Sciences, University of Essex, Wivenhoe Park, Colchester, CO4 3SQ, UK \\ ${ }^{2}$ Department of Mathematical Sciences, University of Essex, Wivenhoe Park, Colchester, CO4 3SQ, UK \\ ${ }^{3}$ Department of Mathematics, University of Leicester, Leicester, LE1 7RH, UK
}

\begin{abstract}
The release of chemicals following herbivore grazing on primary producers may provide feeding cues to carnivorous predators, thereby promoting multitrophic interactions. In particular, chemicals released following grazing on phytoplankton by microzooplankton herbivores have been shown to elicit a behavioural foraging response in carnivorous copepods, which may use this chemical information as a mechanism to locate and remain within biologically productive patches of the ocean. In this paper, we use a $1 \mathrm{D}$ spatial reaction-diffusion model to simulate a tri-trophic planktonic system in the water column, where predation at the top trophic level (copepods) is affected by infochemicals released by the primary producers forming the bottom trophic level. The effect of the infochemical-mediated predation is investigated by comparing the case where copepods forage randomly to the case where copepods adjust their vertical position to follow the distribution of grazing-induced chemicals. Results indicate that utilization of infochemicals for foraging provides fitness benefits to copepods and stabilizes the system at high nutrient load, whilst also forming a possible mechanism for phytoplankton bloom formation. We also investigate how the copepod efficiency to respond to infochemicals affects the results, and show that small increases $(2 \%)$ in the ability of copepods to sense infochemicals can promote their persistence in the system. Finally we argue that effectively employing infochemicals for foraging can be an evolutionarily stable strategy for copepods.
\end{abstract}

Keywords and phrases: infochemicals, dimethylsulphide (DMS), multitrophic interactions, vertical plankton distribution, food-web interactions, evolutionarily stable strategy

Mathematics Subject Classification: 92D25, 92D40

\section{Introduction}

Information-conveying chemicals (infochemicals) play an important role in marine food-web interactions [18]. For non-visual organisms, such as planktonic copepods, infochemicals provide a crucial source of information for locating prey and mates in an otherwise nutritionally sparse three-dimensional environment [e.g. 23].

${ }^{*}$ Corresponding author. E-mail: ndlewi@essex.ac.uk 
Numerous chemicals are released into the marine environment by phytoplankton, and affect copepod foraging in a number of ways. Copepods avoid certain phytoplankton-derived compounds [44, 45] while others, such as phycotoxins $[5,53]$ and polyunsaturated aldehydes [36], have deleterious effects on copepod survival and reproduction. Copepods are attracted to algal amino acids $[15,38]$ and secondary metabolites [49], suggesting that some phytoplankton exudates may function as infochemical cues to help copepods locate suitable prey items.

A number of modelling studies in the literature have focused on the role of phytoplankton-derived toxins in plankton food chain interactions [e.g. 5]. However, the role of predator attraction to phytoplankton exudates has received little attention [28]. Here we consider phytoplankton-derived dimethylsulphide (DMS) as an example of one of potentially many infochemicals that may mediate interactions over three trophic levels. While the effect of DMS on copepod foraging success remains unresolved [3], we choose DMS as an example chemical that has been well studied due to its potential impact in climate regulation [4]. Furthermore, DMS is increasingly being recognized as an important marine infochemical, with a number of studies reporting attraction by a wide range of taxa, both in the water [49] and through airborne emissions fluxed to the atmosphere [7,35]. DMS has been shown to elicit a foraging response in the copepod Temora longicornis [49] suggesting that copepods may use this chemical information when searching for prey. The release of DMS is rapidly accelerated following microzooplankton grazing on phytoplankton $[1,55]$. The fact that copepods can detect and modify their behaviour in response to DMS suggests that, in principle, the grazing-induced release of DMS can promote multitrophic interactions between phytoplankton, microzooplankton and copepods by enhancing the copepod search for microzooplankton prey, potentially releasing excessive grazing pressure from phytoplankton [48].

Lewis et al. (2012) [27] explored a non-spatial model of the interactions between phytoplankton, microzooplankton and copepods under the influence of infochemicals produced following microzooplankton grazing. They found that inclusion of an infochemical term in the model stabilized the population dynamics and could promote the formation of phytoplankton blooms [27]. The vertical distribution of phytoplankton in the oceans is highly heterogeneous, but depth profiles have shown DMS concentrations to correspond well to the chlorophyll maxima [47], potentially allowing vertically-migrating copepods to use gradients of DMS to locate and remain within profitable foraging patches. Here we extend the work of Lewis et al. (2012) [27] to consider infochemical-mediated tritrophic interactions in one vertical dimension. We construct a 1-d reaction-diffusion food web model to simulate the grazing-induced production of chemicals in the water column, with an additional ordinary differential equation to model the distribution of vertically migrating copepods foraging under the influence of these chemicals. We show that this model reproduces the main results from Lewis et al. (2012) [27], that infochemical-mediated predation has a stabilizing effect on the population dynamics and may promote phytoplankton bloom formation, whilst also demonstrating that utilization of infochemicals provides fitness benefits to copepods, and can be evolutionarily beneficial for this species.

\section{The Model}

The following model describes the interactions between small infochemical-producing phytoplankton $(P)$, microzooplankton $(M)$ and copepods $(Z)$ between the surface $(h=0)$ and base of the euphotic zone $(h=H)$. Chemicals $(C)$ are released into the water column following microzooplankton grazing on phytoplankton, which may then act as infochemical foraging cues for copepods to locate microzooplankton prey. The model is given by: 


$$
\begin{aligned}
\frac{\partial P(h, t)}{\partial t} & =D \frac{\partial^{2} P}{\partial h^{2}}+r \exp \left(-\phi h-\omega \int_{0}^{h} P(h) d h\right) P\left(1-\frac{P}{K}\right)-m P-\frac{g P M}{k_{1}+P} \\
\frac{\partial M(h, t)}{\partial t} & =D \frac{\partial^{2} M}{\partial h^{2}}+\frac{\gamma g P M}{k_{1}+P}-\mu M-\frac{\beta M \bar{Z}}{k_{2}+M} z(h) \\
\frac{\partial C(h, t)}{\partial t} & =D \frac{\partial^{2} C}{\partial h^{2}}+\frac{\eta g P M}{k_{1}+P}-\nu C \\
\frac{d \overline{Z(t)}}{d t} & =\epsilon \frac{\bar{Z}}{H} \int_{0}^{H} \frac{\beta M}{k_{2}+M} z(h) d h-\delta \bar{Z}
\end{aligned}
$$

where $P, M$ and $C$ are the densities/concentration at depth $h$ and $\bar{Z}$ is the average density of copepods over the entire water column. The model is subject to the following boundary conditions to prevent the plankton species from leaving the euphotic zone, and to allow the flux of chemicals to the atmosphere:

$$
\begin{gathered}
\frac{\partial P(0, t)}{\partial h}=\frac{\partial P(H, t)}{\partial h}=0 \\
\frac{\partial M(0, t)}{\partial h}=\frac{\partial M(H, t)}{\partial h}=0 \\
\frac{\partial C(0, t)}{\partial h}=F C, \quad \frac{\partial C(H, t)}{\partial h}=0
\end{gathered}
$$

In the model, phytoplankton are assumed to grow logistically with maximum rate of growth $r$ and carrying capacity $K$, where $r$ incorporates both the maximum resource availability and incident light intensity [42]. For the sake of simplicity, we do not explicitly consider depletion of nutrients in the water. Phytoplankton growth is limited by the amount of light available for photosynthesis. This decreases exponentially with depth due to two processes: (i) absorption by water, where $\phi$ is the light attenuation coefficient and (ii) shading of phytoplankton in deep layers by phytoplankton in higher layers, which is taken to be the integral biomass of phytoplankton between $h$ and the surface multiplied by the selfshading coefficient $\omega$. This results in a vertical heterogeneity of phytoplankton. Phytoplankton are also subject to a natural mortality $m$, which is assumed to occur from processes such as sinking out of the euphotic zone and predation from higher trophic levels.

Microzooplankton and copepods follow Holling type II functional responses [19] with maximum grazing/predation rates $g \& \beta$ and half-saturation constants $k_{1} \& k_{2}$ respectively. Microzooplankton convert grazed phytoplankton into new biomass with efficiency $\gamma$ and are subject to natural mortality at a linear rate $\mu$, while copepods convert microzooplankton with efficiency $\epsilon$ and are subject to natural mortality at a linear rate $\delta$. It is assumed that copepods prey on microzooplankton only. This is justified through experimental studies which have shown small DMS-producing phytoplankton to be a suboptimal food source for copepods [33], who select the nutritionally superior microzooplankton when presented with a choice of prey [e.g. 17].

Chemicals are produced at a rate $\eta$ proportional to the rate of grazing of microzooplankton on phytoplankton $[1,55]$ and leave the system at a rate $\nu$ due to processes such as photoxidation and bacterial consumption [46]. The flux of chemicals to the atmosphere is accounted for by the boundary conditions (Eq. 2.7), where $F$ is the flux rate.

It is assumed that phytoplankton and microzooplankton have limited swimming abilities and are therefore subject to a turbulent diffusion, $D$, due to the surrounding fluid movement. The diffusion coefficient of DMS is similar to that obtained from phytoplankton and microzooplankton swimming experiments in the laboratory $[43,54]$, therefore we assume chemicals are subject to the same turbulent diffusion. For the sake of simplicity, we further assume turbulent diffusion is the only mode of transport in the model, and do not take into account factors such as hydrodynamic circulation. Copepods have swimming speeds that 
are higher than turbulent velocity fluctuations and can therefore move independently of the surrounding water flow $[57,58]$. It is for this reason that we model copepods in terms of the integral population size over the water column by an ordinary, rather than a partial, differential equation. In particular, copepods exhibit vertical migrations, often migrating between surface and deep layers several times over short time periods of 0.5-2 days [32], making the active movement of copepods a fast process in comparison to the passive diffusion of phytoplankton, microzooplankton and chemicals. It would therefore be incorrect to assign an individual copepod to a fixed horizontal layer in the water column in this model time-scale [32].

The relative density of copepods follows the vertical distribution given by the function $z(h)$, so that integration over the whole column gives $H$ (Eq. 2.4). We consider two different formulations for $z(h)$ in order to compare the following scenarios:

(i) Copepods are homogeneously distributed in the water column i.e. they forage randomly with no mechanism to locate microzooplankton prey:

$$
z(h)=1
$$

(ii) Copepods follow the ideal free distribution in its simplest form [IFD; 16,25] based on infochemicals i.e. copepods adjust their vertical position to follow the instantaneous distribution of chemicals. We suggest here that the copepod response to infochemicals is not concentration dependent. This formulation is given by:

$$
z(h)=\frac{C(h)}{\bar{C}}, \text { with } \bar{C}=\frac{1}{H} \int_{0}^{H} C(h) d h
$$

We impose zero-flux boundary conditions for phytoplankton (Eq. 2.5) and microzooplankton (Eq. 2.6) at the surface $(h=0)$ and base $(h=H)$ of the euphotic zone. We also impose a zero-flux boundary condition for chemicals at the bottom of the euphotic zone, but use a Neumann boundary condition at the surface (Eq. 2.7) to account for the flux of chemicals to the atmosphere.

Parameter values and ranges are based on values found in the literature, and are summarized in Table 1. We note that the base mortality rate for copepods is slightly lower than reported. This was to prevent copepods from heading to extinction when modelled to forage randomly, allowing us to work with a tritrophic system.

We consider the depth of the euphotic zone to be $H=80 \mathrm{~m}$ and split this into 300 depth levels to gain a sufficient degree of accuracy. Numerical simulations are begun assuming phytoplankton, microzoo-

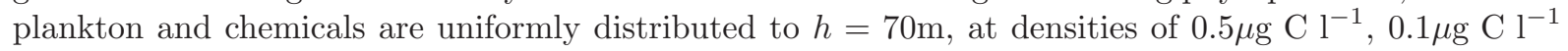
and $0.001 \mathrm{nM}$ respectively, below which the initial density/concentration is zero. The initial density of copepods is $0.05 \mu \mathrm{g} \mathrm{C}^{-1}$ throughout the water column. We use a time resolution of $\Delta t=0.01 \mathrm{~d}$. Experimenting with other depth and time resolutions reveals the qualitative behaviour of the model to be robust. All one- and two-parameter bifurcation diagrams were constructed by numerically solving Eqs. (2.1-2.4). Pseudo code for the method used to carry out these bifurcation analyses is given in Appendix A.

The dynamics of the model were explored by extensive numerical simulation in MATLAB [29]. We used the finite-difference method based on the explicit scheme [21] for numerical simulation of the model equations. The integrals in the equations were computed based on the trapezoidal rule [21]. In the following analysis simulations are run for 2000 days unless otherwise stated. This was to allow solutions to tend to equilibrium. We consider copepod extinction to occur if $\bar{Z}<0.1 \mu \mathrm{g} \mathrm{C}^{-1}$ at the end of the simulation (see Appendix A). Likewise, phytoplankton bloom formation is assumed to have occurred if an equilibrium is obtained where the density of phytoplankton in the surface layer, $P_{\text {surf }}$, is greater than $50 \mu \mathrm{g} \mathrm{C} \mathrm{l}^{-1}$. 
(a)

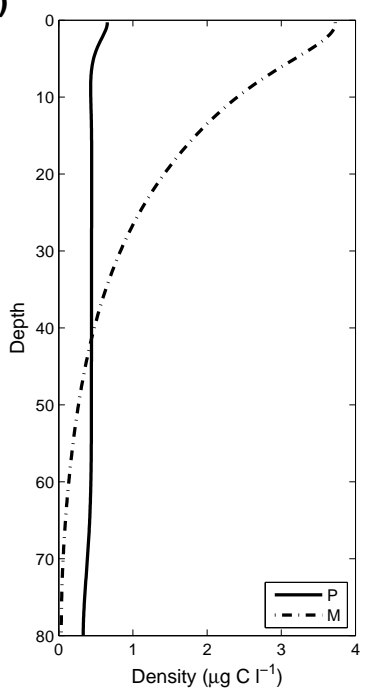

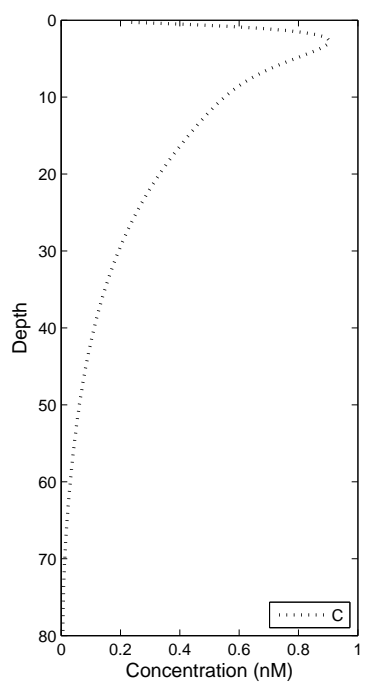

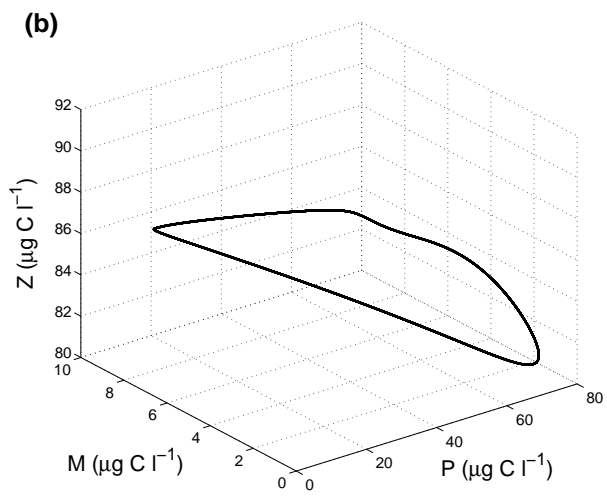

(c)
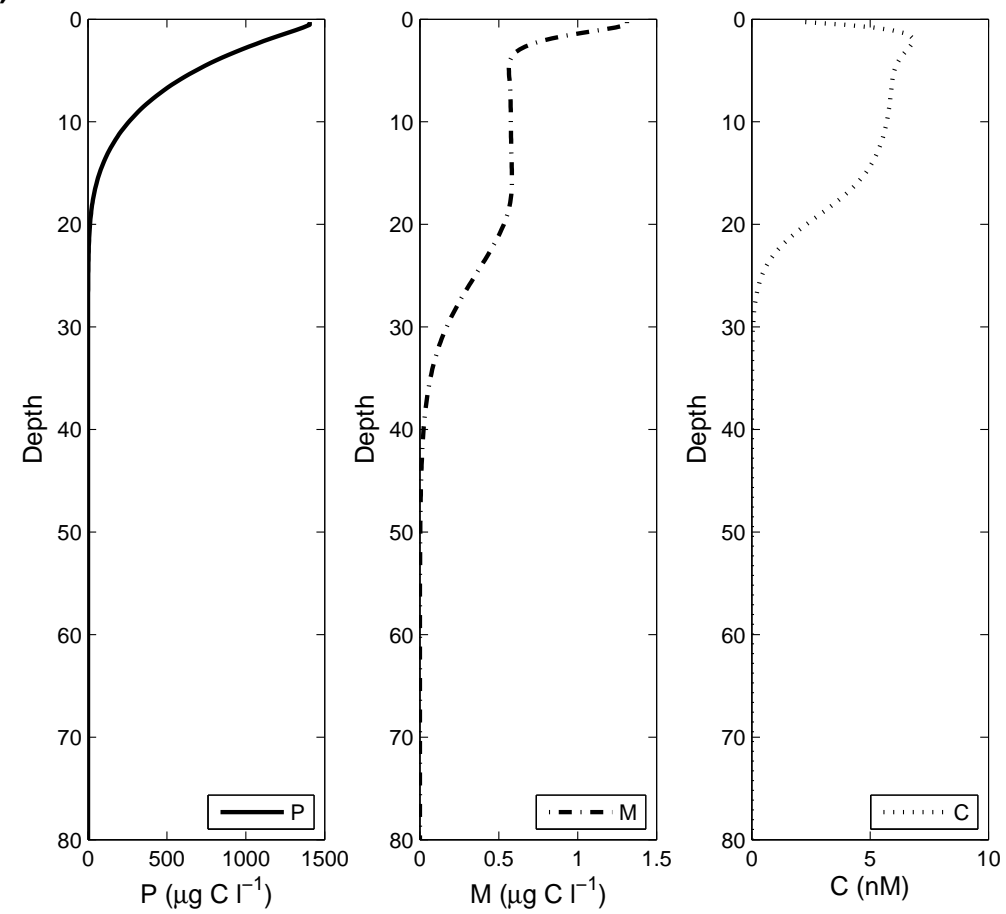

Figure 1. The three main dynamical regimes displayed by the model: (a) the predatorprey profile $(\mathrm{PP})$, produced using the fixed values in Table 1 when copepods forage randomly, with $\delta=0.015$ (copepod mortality) to ensure copepods become extinct, (b) limit cycle behaviour (LC), showing the mean plankton densities, produced using the fixed values in Table 1 when copepods forage randomly and (c) the persistence steady state, produced using the fixed values in Table 1 when copepods follow the ideal free distribution based on chemicals. 
TABLE 1. Model parameter values. The parameter values given here are fixed unless otherwise stated.

\begin{tabular}{ccccc}
\hline Parameter & Definition & Units & Fixed value & Range \\
\hline$r$ & Phytoplankton intrinsic growth rate & $\mathrm{d}^{-1}$ & 1.5 & $0.1-2[32]$ \\
$K$ & Phytoplankton carrying capacity & $\mu \mathrm{g} \mathrm{C} \mathrm{l}^{-1}$ & 2000 & $50-\infty[32]$ \\
$\phi$ & Light attenuation coefficient & $\mathrm{m}^{-1}$ & 0.05 & $0.005-0.15[32]$ \\
$\omega$ & Self-shading coefficient & $1 /\left({\left.\mathrm{m} \mu \mathrm{g} \mathrm{l}^{-1}\right)}^{-1}\right.$ & 0.002 & $0.0005-0.005[32]$ \\
$g$ & Microzooplankton grazing rate & $\mathrm{d}^{-1}$ & 7.5 & $2-12[9]$ \\
$\beta$ & Copepod predation rate & $\mathrm{d}^{-1}$ & 1.4 & $0.6-1.4[11]$ \\
$k_{1}$ & Half saturation constant & $\mu \mathrm{g} \mathrm{C} \mathrm{l}^{-1}$ & 20 & $20-100[11]$ \\
$k_{2}$ & Half saturation constant & $\mu \mathrm{g} \mathrm{C}^{-1}$ & 60 & $20-100[11]$ \\
$\gamma$ & Microzooplankton grazing efficiency & - & 0.3 & $0.3-0.5[22]$ \\
$\epsilon$ & Copepod predation efficiency & - & 0.7 & $0.3-0.7[22]$ \\
$m$ & Phytoplankton mortality & $\mathrm{d}^{-1}$ & 0.02 & $0-0.3[13]$ \\
$\mu$ & Microzooplankton mortality & $\mathrm{d}^{-1}$ & 0.05 & $0.015-0.15[11]$ \\
$\delta$ & Copepod mortality & $\mathrm{d}^{-1}$ & 0.01 & $0.015-0.15[11]$ \\
$\eta$ & Chemical production & $\mathrm{nmol}^{-1} \mu \mathrm{g} \mathrm{C}$ & 1 & $0.02-1.4[30,55]$ \\
$\nu$ & Chemical removal rate & $\mathrm{d}^{-1}$ & 0.7 & $0.7-2.2[13]$ \\
$D$ & Diffusion coefficient & $\mathrm{m}^{2} \mathrm{~d}^{-1}$ & 1 & $1-10[2]$ \\
$F$ & Chemical flux to the atmosphere & $\mathrm{d}^{-1}$ & 0.13 & $0.13[13]$ \\
\hline
\end{tabular}

\section{Results}

To gain an initial insight into the behaviour of the model, simulations were run where parameters took values at the boundaries of each parameter range in Table 1, whilst all other parameters were kept at their fixed values. These initial simulations revealed three main dynamical regimes. The first is the predator-prey vertical profile (PP), where copepods become extinct from the system and phytoplankton and microzooplankton densities tend to a heterogeneous stable steady state (Figure 1a). This profile is in agreement with that of [10] for a planktonic predator-prey system. The second is limit cycle behaviour (LC), where the mean (depth-averaged) plankton densities exhibit periodic oscillations (Figure 1b). The third is the persistence profile, where all plankton populations tend to a heterogeneous steady state (Figure 1c). There were three cases which led to a different steady state profile (O), where $P>M \quad \forall \quad P, M$. For each of these cases phytoplankton were unable to bloom. The results of these initial simulations are summarized in Table 2.

The purpose of the following sections is to assess the effect of infochemical-mediated foraging on (1) copepod fitness, (2) system stability and (3) phytoplankton bloom formation. These sections will provide detail on the above results while exploring the dynamics of the model across the full range of a few parameters of interest.

\subsection{Copepod persistence and abundance}

Using infochemicals to locate microzooplankton prey appears to provide a number of fitness benefits to copepods. In particular, there were seven parameterizations where infochemically informed copepods could persist in the system, but not randomly foraging copepods (Table 2). In contrast, there was only one parameterization in which the equilibrium density of randomly foraging copepods was greater than that of chemically informed copepods, this being in a low carrying capacity environment $\left(K=50 \mu \mathrm{g} \mathrm{C}^{-1}\right)$. However, as will be shown in section 4 , this does not necessarily mean that foraging randomly is the better strategy in this case.

Here we carry out bifurcation analyses on the copepod mortality and feeding parameters to further assess the effect of infochemicals on copepod fitness. 
TABLE 2. Results from using the lower bound (LB) and upper bound (UB) of the parameter ranges of Table 1 in the model given by Eqs. 2.1-2.4, keeping all other parameters at the fixed value (Table 1). Solutions tend to either a stable predator-prey profile (PP) as in Figure 1a, a limit cycle (LC) as in Figure 1b, a stable persistence steady state $(\mathrm{SS})$ as in Figure 1c or other (O). Copepods are said to persist (indicated by ticks) if $\bar{Z} \geq 0.1 \mu \mathrm{g} \mathrm{C}^{-1}$ at the end of the simulation. The copepod density is given in the case of persistence steady state (SS). Phytoplankton are said to bloom (indicated by ticks) if $P_{\text {surf }} \geq 50 \mu \mathrm{g} \mathrm{C}^{-1}$ at the end of the simulation. The phytoplankton ability to bloom is recorded only if an equilibrium is reached. Simulations are run for 2000 time steps.

\begin{tabular}{|c|c|c|c|c|c|c|c|}
\hline \multirow[b]{2}{*}{ Parameter } & \multirow[b]{2}{*}{ Value } & \multicolumn{3}{|c|}{ Randomly foraging copepods } & \multicolumn{3}{|c|}{ Chemically informed copepods } \\
\hline & & Solution & Copepods & Bloom & Solution & Copepods & Bloom \\
\hline$r$ & $\begin{array}{c}\mathrm{LB}=0.1 \\
\mathrm{UB}=2\end{array}$ & $\begin{array}{c}\mathrm{O} \\
\mathrm{LC}\end{array}$ & $\begin{array}{l}x \\
y\end{array}$ & $\begin{array}{l}x \\
-\end{array}$ & $\begin{array}{c}\mathrm{O} \\
\mathrm{SS}\end{array}$ & $\begin{array}{c}x \\
21.9\end{array}$ & $\begin{array}{l}x \\
y\end{array}$ \\
\hline$K$ & $\begin{array}{c}\mathrm{LB}=50 \\
\mathrm{UB}=2000\end{array}$ & $\begin{array}{c}\mathrm{O} \\
\mathrm{LC}\end{array}$ & $\begin{array}{c}44.4 \\
\checkmark\end{array}$ & $\begin{array}{l}x \\
x\end{array}$ & $\begin{array}{l}\text { SS } \\
\text { SS }\end{array}$ & $\begin{array}{l}15.5 \\
21.4\end{array}$ & $\begin{array}{l}x \\
\checkmark\end{array}$ \\
\hline$\phi$ & $\begin{array}{c}\mathrm{LB}=0.005 \\
\mathrm{UB}=0.15\end{array}$ & $\begin{array}{l}\mathrm{LC} \\
\mathrm{PP}\end{array}$ & $\begin{array}{l}5 \\
x\end{array}$ & $\bar{x}$ & $\begin{array}{l}\text { SS } \\
\text { SS }\end{array}$ & $\begin{array}{l}21.4 \\
21.2\end{array}$ & $\begin{array}{l}\checkmark \\
\checkmark\end{array}$ \\
\hline$\omega$ & $\begin{array}{c}\mathrm{LB}=0.0005 \\
\mathrm{UB}=0.005\end{array}$ & $\begin{array}{l}\mathrm{LC} \\
\mathrm{LC}\end{array}$ & $\begin{array}{l}\checkmark \\
\checkmark\end{array}$ & $\begin{array}{l}- \\
-\end{array}$ & $\begin{array}{l}\text { SS } \\
\text { SS }\end{array}$ & $\begin{array}{l}25.4 \\
19.9\end{array}$ & $\begin{array}{l}\checkmark \\
\checkmark\end{array}$ \\
\hline$g$ & $\begin{array}{c}\mathrm{LB}=2 \\
\mathrm{UB}=12\end{array}$ & $\begin{array}{l}\mathrm{LC} \\
\mathrm{PP}\end{array}$ & $\begin{array}{l}\checkmark \\
x\end{array}$ & $\bar{x}$ & $\begin{array}{l}\text { SS } \\
\text { SS }\end{array}$ & $\begin{array}{l}6.92 \\
30.1\end{array}$ & $\begin{array}{l}\checkmark \\
\checkmark\end{array}$ \\
\hline$\beta$ & $\begin{array}{l}\mathrm{LB}=0.6 \\
\mathrm{UB}=1.4\end{array}$ & $\begin{array}{l}\text { PP } \\
\text { LC }\end{array}$ & $\begin{array}{l}x \\
\checkmark\end{array}$ & $\begin{array}{l}x \\
x\end{array}$ & $\begin{array}{l}\text { SS } \\
\text { SS }\end{array}$ & $\begin{array}{l}38.4 \\
21.4\end{array}$ & $\begin{array}{l}\checkmark \\
\checkmark\end{array}$ \\
\hline$k_{1}$ & $\begin{array}{c}\mathrm{LB}=20 \\
\mathrm{UB}=100\end{array}$ & $\begin{array}{l}\mathrm{LC} \\
\mathrm{LC}\end{array}$ & $\begin{array}{l}2 \\
d\end{array}$ & - & $\begin{array}{l}\text { SS } \\
\text { SS }\end{array}$ & $\begin{array}{l}21.4 \\
17.3\end{array}$ & $\begin{array}{l}\checkmark \\
\checkmark\end{array}$ \\
\hline$k_{2}$ & $\begin{array}{c}\mathrm{LB}=20 \\
\mathrm{UB}=100\end{array}$ & $\begin{array}{l}\mathrm{LC} \\
\mathrm{PP}\end{array}$ & $\begin{array}{l}5 \\
x\end{array}$ & $\bar{x}$ & $\begin{array}{l}\text { SS } \\
\text { SS }\end{array}$ & $\begin{array}{l}9.23 \\
30.5\end{array}$ & $\begin{array}{l}d \\
d\end{array}$ \\
\hline$\gamma$ & $\begin{array}{l}\mathrm{LB}=0.3 \\
\mathrm{UB}=0.5\end{array}$ & $\begin{array}{l}\mathrm{LC} \\
\mathrm{LC}\end{array}$ & $\begin{array}{l}\checkmark \\
\checkmark\end{array}$ & - & $\begin{array}{l}\text { SS } \\
\text { SS }\end{array}$ & $\begin{array}{l}21.4 \\
36.1\end{array}$ & $\begin{array}{l}\checkmark \\
\checkmark\end{array}$ \\
\hline$\epsilon$ & $\begin{array}{l}\mathrm{LB}=0.3 \\
\mathrm{UB}=0.7\end{array}$ & $\begin{array}{l}\text { PP } \\
\mathrm{LC}\end{array}$ & $\begin{array}{l}x \\
\checkmark\end{array}$ & $\begin{array}{l}x \\
x\end{array}$ & $\begin{array}{l}\text { SS } \\
\text { SS }\end{array}$ & $\begin{array}{l}16.4 \\
21.4\end{array}$ & $\begin{array}{l}\checkmark \\
\checkmark\end{array}$ \\
\hline$m$ & $\begin{array}{c}\mathrm{LB}=0 \\
\mathrm{UB}=0.3\end{array}$ & $\begin{array}{l}\mathrm{LC} \\
\mathrm{PP}\end{array}$ & $\begin{array}{l}5 \\
x\end{array}$ & $\bar{x}$ & $\begin{array}{l}\text { SS } \\
\text { SS }\end{array}$ & $\begin{array}{l}34.2 \\
8.32\end{array}$ & $\checkmark$ \\
\hline$\mu$ & $\begin{array}{c}\mathrm{LB}=0.015 \\
\mathrm{UB}=0.15\end{array}$ & $\begin{array}{l}\mathrm{LC} \\
\mathrm{LC}\end{array}$ & $\begin{array}{l}2 \\
\checkmark\end{array}$ & - & $\begin{array}{l}\text { SS } \\
\text { SS }\end{array}$ & $\begin{array}{l}21.8 \\
20.2\end{array}$ & $\begin{array}{l}2 \\
\checkmark\end{array}$ \\
\hline$\delta$ & $\begin{array}{c}\mathrm{LB}=0.015 \\
\mathrm{UB}=0.15\end{array}$ & $\begin{array}{l}\text { PP } \\
\text { PP }\end{array}$ & $\begin{array}{l}x \\
x\end{array}$ & $\begin{array}{l}x \\
x\end{array}$ & $\begin{array}{l}\text { SS } \\
\text { PP }\end{array}$ & $\begin{array}{c}19.0 \\
x\end{array}$ & $\begin{array}{l}\checkmark \\
x\end{array}$ \\
\hline$\eta$ & $\begin{array}{c}\mathrm{LB}=0.02 \\
\mathrm{UB}=1.4\end{array}$ & $\begin{array}{l}\mathrm{LC} \\
\mathrm{LC}\end{array}$ & $\begin{array}{l}\checkmark \\
\checkmark\end{array}$ & - & $\begin{array}{l}\text { SS } \\
\text { SS }\end{array}$ & $\begin{array}{l}21.4 \\
21.4\end{array}$ & $\begin{array}{l}\checkmark \\
\checkmark\end{array}$ \\
\hline$\nu$ & $\begin{array}{l}\mathrm{LB}=0.7 \\
\mathrm{UB}=2.2\end{array}$ & $\begin{array}{l}\mathrm{LC} \\
\mathrm{LC}\end{array}$ & $\begin{array}{l}\checkmark \\
\checkmark\end{array}$ & $\begin{array}{l}- \\
-\end{array}$ & $\begin{array}{l}\text { SS } \\
\text { SS }\end{array}$ & $\begin{array}{l}21.4 \\
21.0\end{array}$ & $\begin{array}{l}\checkmark \\
\checkmark\end{array}$ \\
\hline
\end{tabular}

The bifurcation diagrams in Figure 2 show the mean (depth-averaged) plankton densities for different values of the copepod mortality rate, $\delta$. When copepods are assumed to forage randomly, the plankton densities exhibit oscillations until $\delta=0.025 \mathrm{~d}^{-1}$ where the copepod population becomes extinct, and the phytoplankton and microzooplankton densities stabilize at low levels (Figure 2a). Assuming that copepods locate microzooplankton prey through chemodetection initially stabilizes the system until $\delta=$ $0.015 \mathrm{~d}^{-1}$ where solutions begin to oscillate (Figure $2 \mathrm{~b}$ ). In this situation copepods are able to survive 
(a)

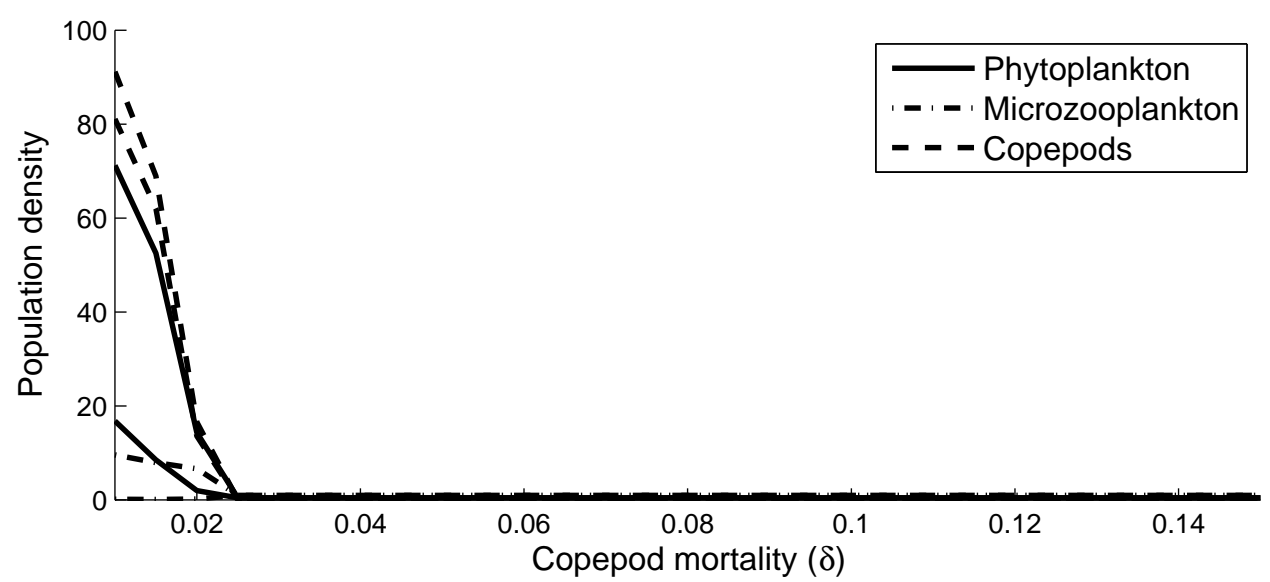

(b)

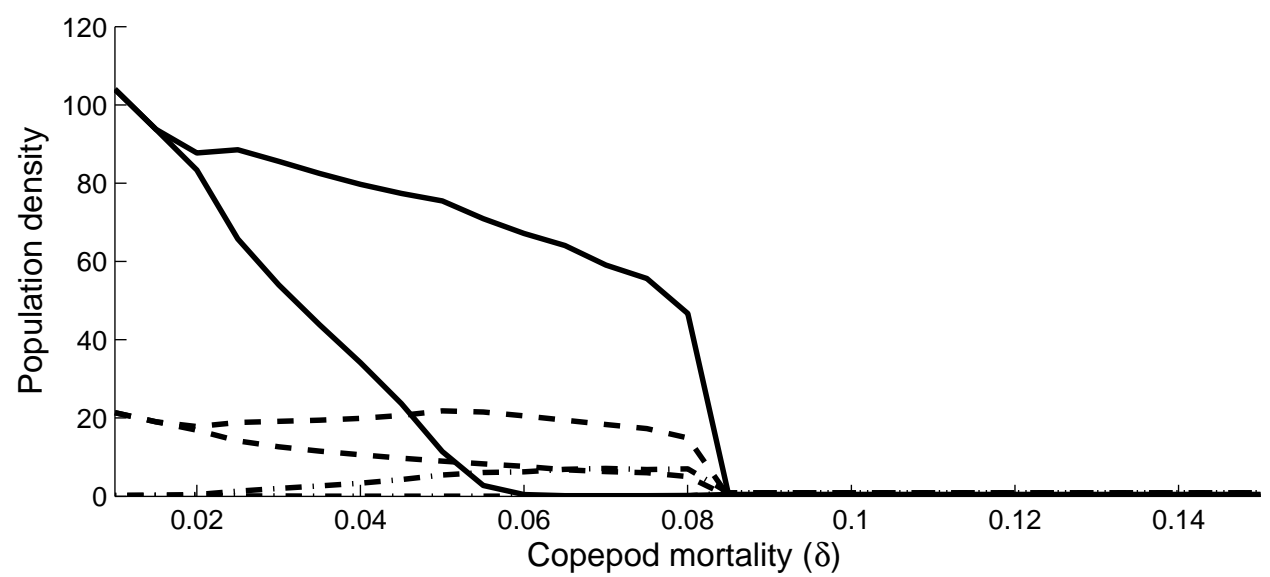

FiguRE 2. Bifurcation diagrams showing the space-average plankton densities for different levels of copepod mortality, $\delta$, when (a) copepods forage randomly and (b) copepods forage according to the ideal free distribution based on chemicals, produced using the fixed values in Table 1 . The diagram shows the equilibrium densities of the stable steady state or the maximum and minimum densities of the stable limit cycle.

in the system until $\delta=0.085 \mathrm{~d}^{-1}$, meaning that copepods that improve the efficiency of their search through chemodetection can survive under greater predation pressure from higher trophic levels. It should be noted that there is a small range of copepod mortality values $\left(\delta<0.02 \mathrm{~d}^{-1}\right)$ where the density of randomly foraging copepods is greater than that of chemically informed copepods, suggesting that it is beneficial for copepods to forage randomly rather than through chemodetection. Likewise, a similar situation is observed over the full range of the phytoplankton carrying capacity, $K$ (Figure 4 ). We emphasize here that this occurs only for values of $\delta$ below the reported range given in Table 1 , and that it was necessary to use a low value of $\delta$ to preserve a tritrophic system, and prevent randomly foraging copepods from becoming extinct in this scenario.

Table 2 shows copepods to become extinct when parameterized with a low predation rate or conversion efficiency suggesting that, in the absence of infochemical cues, copepods are not efficient enough predators to persist in the system. The two-parameter bifurcation maps in Figure 3 detail copepod persistence and system stability in $\beta-\epsilon$ (copepod predation rate - predation efficiency) parameter space for randomly foraging and infochemically informed copepods. It can been seen from Figure 3a that randomly foraging copepods require large values of both the predation rate, $\beta$, and conversion efficiency, $\epsilon$, to persist in the 
(a)

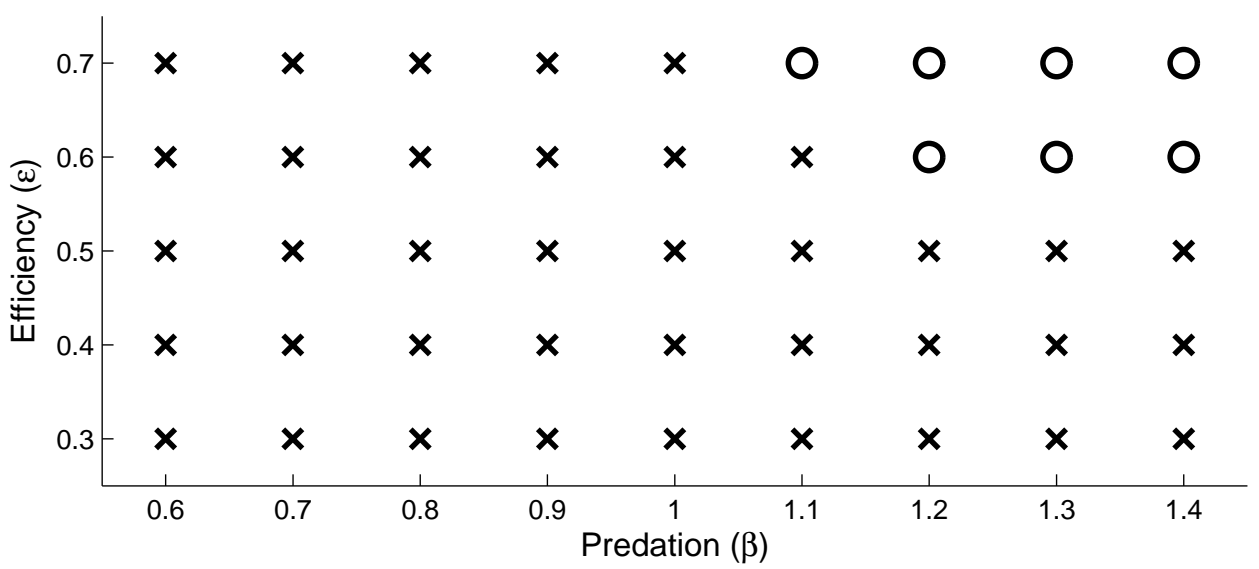

(b)

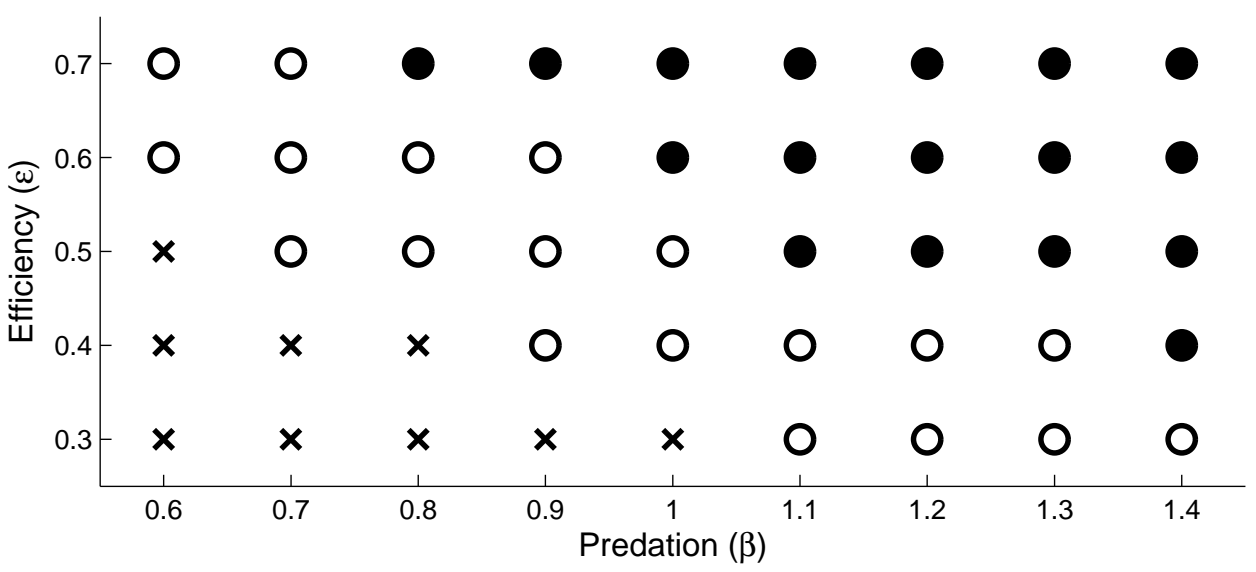

Figure 3. Two-parameter bifurcation maps for the copepod feeding parameters $\beta$ and $\epsilon$ when (a) copepods forage randomly and (b) copepods forage according to the ideal free distribution based on chemicals, produced using the fixed values in Table 1. Different symbols represent different dynamical regimes: closed circles for a heterogeneous stable steady state with copepod persistence, open circles for unstable dynamics with copepod persistence, and crosses for a heterogeneous stable steady state with copepod extinction. It is noted here that the points $(\beta, \epsilon)=(1,0.7),(1.4,0.5)$ in $(\mathrm{a})$ and $(\beta, \epsilon)=(0.8,0.4)$ in (b) required more than 2000 days to reach the given solution.

system whereas Figure 3b shows copepod persistence to be possible for a larger range of parameter values. In particular, copepods can persist in the system with either a low value of $\beta$ or $\epsilon$ provided that the other parameter is high. Furthermore, a stable steady state, as in Figure 1c, is attained over a larger range of parameter combinations when copepods forage according to the ideal free distribution (closed circles in Figure 3). When copepods forage randomly limit cycle behaviour, as in figure 1b, is more likely to occur if copepods persist (open circles in Figure 3). In this situation, less efficient copepod predators are able to persist by utilizing chemodetection to improve the efficiency of their search for microzooplankton prey (Figure 3b).

\subsection{Stabilisation of system dynamics}

Use of the ideal free distribution based on chemicals (Eq. 2.9) in the model appears to have a stabilizing effect on the system dynamics. Table 2 shows all parameterisations which display limit cycle behaviour 
when copepods forage randomly to lead to the stable persistence steady state upon applying the assumption that copepods follow infochemicals. Furthermore, none of the tested parameterizations resulted in limit cycle behaviour when the ideal free distribution based on chemicals was used in the model.

(a)

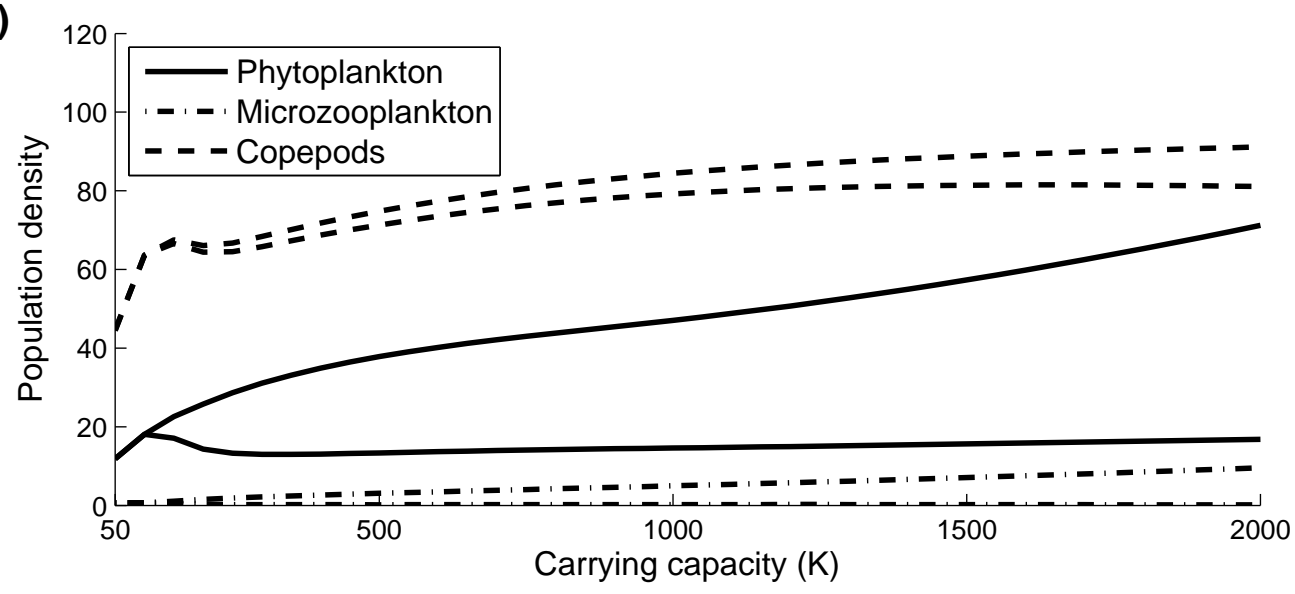

(b)

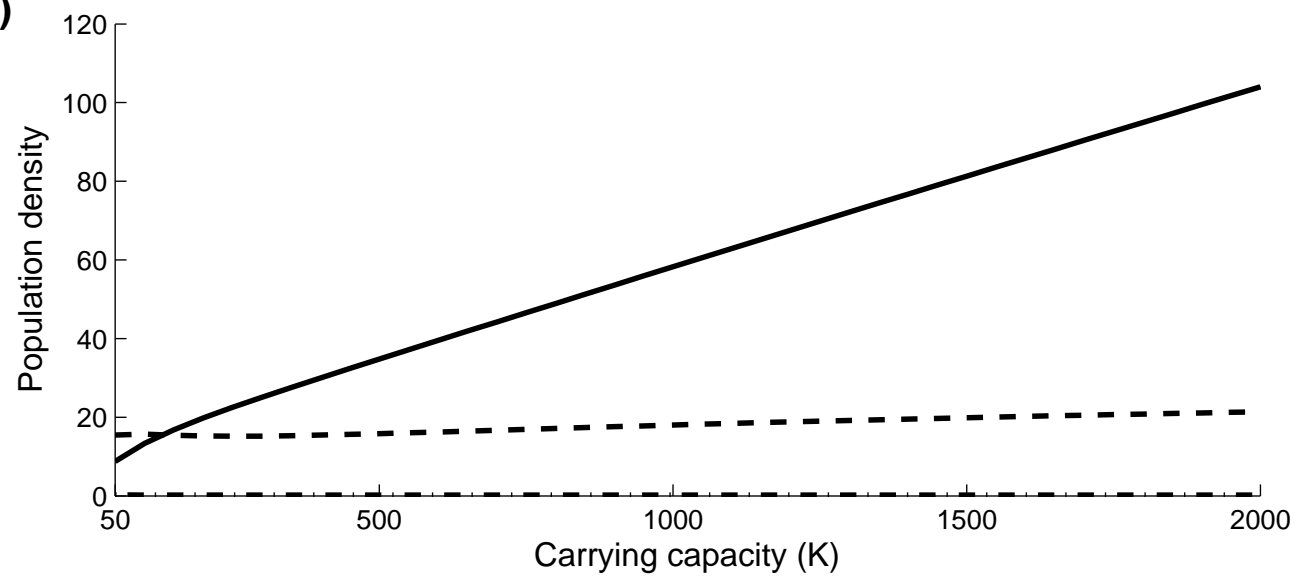

FIgURE 4. Bifurcation diagram showing the space-average plankton densities for different levels of the phytoplankton carrying capacity, $K$, when (a) copepods forage randomly and (b) copepods forage according to the ideal free distribution based on chemicals, produced using the fixed values in Table 1 . The diagram shows the equilibrium densities of the stable steady state or the maximum and minimum densities of the stable limit cycle.

It is a standard result in theoretical ecology that increasing the carrying capacity of the base species in a model has a destabilizing effect on the population dynamics of the system (the Paradox of Enrichment $[39,40])$. The bifurcation diagrams in Figure 4 show the mean (depth-averaged) densities of the plankton species as the phytoplankton carrying capacity is increased. When copepods are assumed to forage randomly the model behaves in the same way as the standard Rosenzweig-MacArthur model [40], where the initial stable steady state becomes destabilized upon eutrophication $(K \approx 100$; Figure $4 \mathrm{a})$. However, when it is assumed that copepods use infochemicals to locate microzooplankton prey the system is stable over the full range of $K$ (Figure $4 \mathrm{~b}$ ). 
For a large range of the phytoplankton carrying capacity $(K>600)$ phytoplankton were present at higher densities when assuming copepods forage through chemodetection rather than foraging randomly, with only a small range of $K$ showing the opposite trend $(K<150)$, supporting the hypothesis that infochemical-mediated predation promotes bloom formation.

\subsection{Phytoplankton bloom formation}

Releasing chemicals that attract the predators of herbivorous microzooplankton appears to function as a mechanism for phytoplankton bloom formation (Table 2). In particular, phytoplankton bloom formation was possible for twenty-seven out of thirty parameterizations when copepods were modelled to follow the ideal free distribution based on chemicals, but was not possible when copepods were modelled to forage randomly.

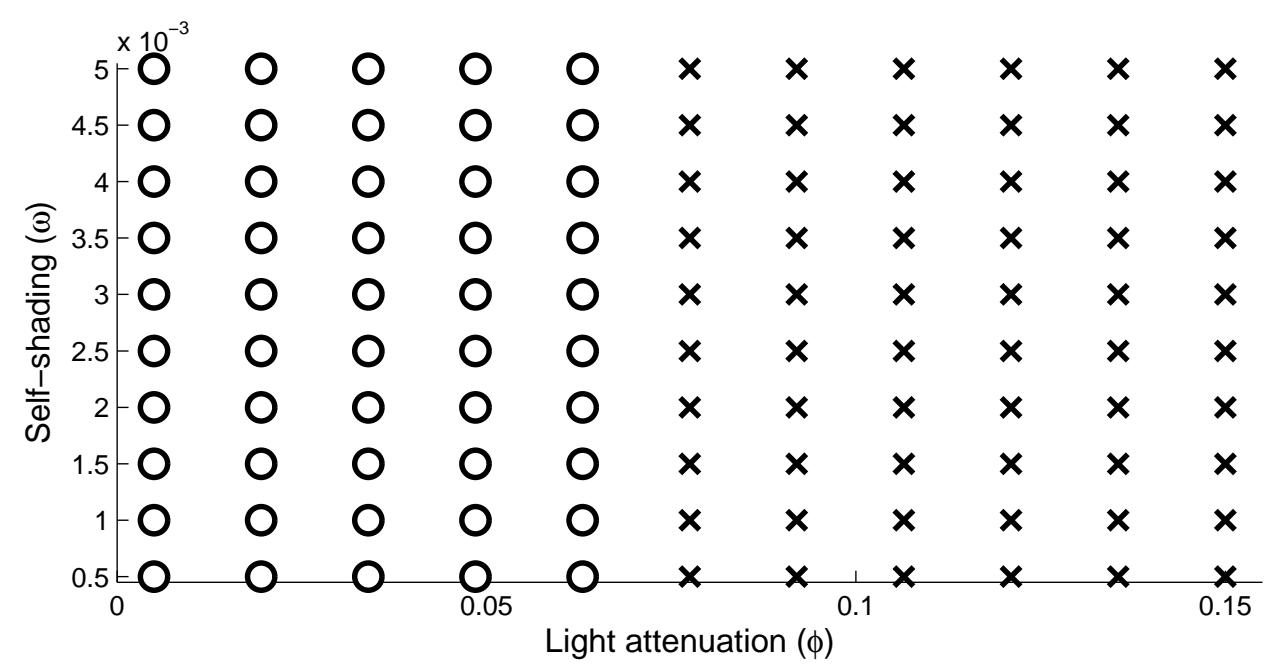

FiguRE 5. Two-parameter bifurcation map for the phytoplankton growth parameters $\phi$ and $\omega$ when copepods forage randomly, produced using the fixed values in Table 1. Different symbols represent different dynamical regimes: open circles for unstable dynamics and crosses for a heterogeneous stable steady state without blooms $\left(P_{\text {surf }}<\right.$ $\left.50 \mu \mathrm{g} \mathrm{C}^{-1}\right)$.

The two-parameter bifurcation map in Figure 5 shows where stability and bloom formation occurs depending on the phytoplankton growth parameters in $\phi-\omega$ parameter space when copepods forage randomly. It can be seen from Figure 5 that for $\phi \leq 0.063$ the system exhibited limit cycle behaviour as in Figure 1b, otherwise the system tended to the predator prey profile as in Figure 1a, meaning that a stable equilibrium where $P_{\text {surf }} \geq 50 \mu \mathrm{g} \mathrm{C} ~^{-1}$ is not obtained for any parameter combination when copepods are assumed to forage randomly. Hence phytoplankton bloom formation is not possible.

Bloom formation was possible for all parameter combinations when copepods were assumed to forage according to the ideal free distribution based on chemicals (figure omitted), although we note here that the points $(\beta, \epsilon)=(0.0195,0.0005)$ and $(\beta, \epsilon)=(0.121,0.0005)$ required more than 2000 days to reach an equilibrium. In this situation, chemicals are released to patches of high biological activity, which are utilized by foraging copepods. The increased copepod predation on microzooplankton releases excessive grazing pressure from phytoplankton, allowing the formation of a bloom. 


\section{Infochemical-mediated foraging as an evolutionarily stable strategy}

The functions $z(h)$ that describe the vertical distribution of copepods (Eqs. $2.8 \& 2.9$ ) assume either copepods make no use of infochemicals, or that copepods can match the distribution of chemicals with $100 \%$ efficiency. In reality, chemicals released into a patch of high biological activity will not span the full depth of the water column (see Figure 1c) and hence copepods would have to make use of other cues in their search for microzooplankton prey [56]. In particular, Woodson et al. (2007) [56] showed copepods to use a range of cue hierarchies to narrow search regions.

Taking this into account we modify the function $z(h)$ to include an additional parameter $\sigma$, which determines the efficiency with which copepods match the distribution of grazing-induced chemicals. In subsequent sections we term this the 'chemical following efficiency'. The new function is given by:

$$
z(h)=1-\sigma+\sigma \frac{C(h)}{\bar{C}}, \text { with } \bar{C}=\frac{1}{H} \int_{0}^{H} C(h) d h .
$$

This formulation combines Eqs. $2.8 \& 2.9$ to allow copepods to forage both randomly and through chemodetection, where the parameter $\sigma$ is the relative contribution of infochemicals in determining the vertical distribution of copepods ( $\sigma=1$ corresponds to $100 \%$ chemical following efficiency). We assume the random foraging proportion of Eq. 4.1 accounts for copepods foraging in layers with no chemicals while the ideal free proportion of 4.1 accounts for copepods foraging within the vicinity of a prey rich patch. We note here that this formulation does not account for copepods foraging through the use of other cues or mechanisms e.g. velocity gradients.

The bifurcation diagrams in Figure 6 show the mean (depth-averaged) plankton densities for different values of the copepod chemical following efficiency, $\sigma$, for two values of the copepod mortality rate, $\delta$. When assuming the fixed parameter values of Table 1 , where the copepod mortality rate is below that reported in the literature $\left(\delta=0.01 \mathrm{~d}^{-1}\right)$, the plankton densities exhibit oscillations until $\sigma=0.79$ (Figure 6a). This means that, for system stabilization to take place and a phytoplankton bloom to occur, as in Figure 1c, copepods must forage with a $79 \%$ chemical efficiency. When the copepod mortality rate is increased to a more realistic value $\left(\delta=0.015 \mathrm{~d}^{-1}\right)$ copepods that forage randomly $(\sigma=0)$ tend to extinction, with phytoplankton and microzooplankton populations tending to a heterogeneous stable steady state at low densities (Figure 1a). However, Figure 6b shows that increasing the copepod chemical efficiency by only $2 \%(\sigma=0.02)$ will allow copepods to persist in the system, with the mean plankton densities exhibiting limit cycle behaviour, as in Figure 1b. For system stabilization and bloom formation to take place, as in Figure 1c, copepods must forage with a $93 \%(\sigma=0.93)$ chemical efficiency (Figure $6 \mathrm{~b})$. Figure 6 shows, for both values of the copepod mortality rate $\delta$, the copepod density to decrease with increasing copepod chemical efficiency (only for $\sigma>0.13$ when $\delta=0.015 \mathrm{~d}^{-1}$ ).

The variation of species densities shown in Figure 6 for a gradual increase of the chemical efficiency $\sigma$ does not resolve the fundamental question about possible advantages of using DMS by copepods. Indeed, the total biomass of fully chemically informed copepods $(\sigma=1)$ is lower compared to that of randomly foraging copepods. Some understanding of possible advantages of following the distribution of DMS in the water column can be obtained based on theoretical methods of adaptive dynamics and game theory $[8,14]$. By implementing those methods, we consider a scenario where a small amount of a new copepod strain (called a 'mutant') with efficiency $\sigma_{2}$ is introduced into the system where the resident strain of copepods with efficiency $\sigma_{1}$ is at some equilibrium dynamical state (this includes both an equilibrium and limit cycle regimes). In the case where the fitness of the mutant is greater than zero then it can successively invade the system and overcompete the resident one. By calling the newly established strain the resident strain, we repeat the same procedure again, etc. The value of the efficiency $\sigma^{*}$, corresponding to the evolutionarily stable strategy will be the one for which invasion of any mutant strain (when initially rare) becomes impossible and which is convergence stable, i.e. locally attracting [8]. Note that we consider that the evolution process acts on a much larger time scale than that of any population oscillations, i.e. variation in $\sigma$ is much slower than that of species densities through a cycle. In this case, mutations in the 
(a)

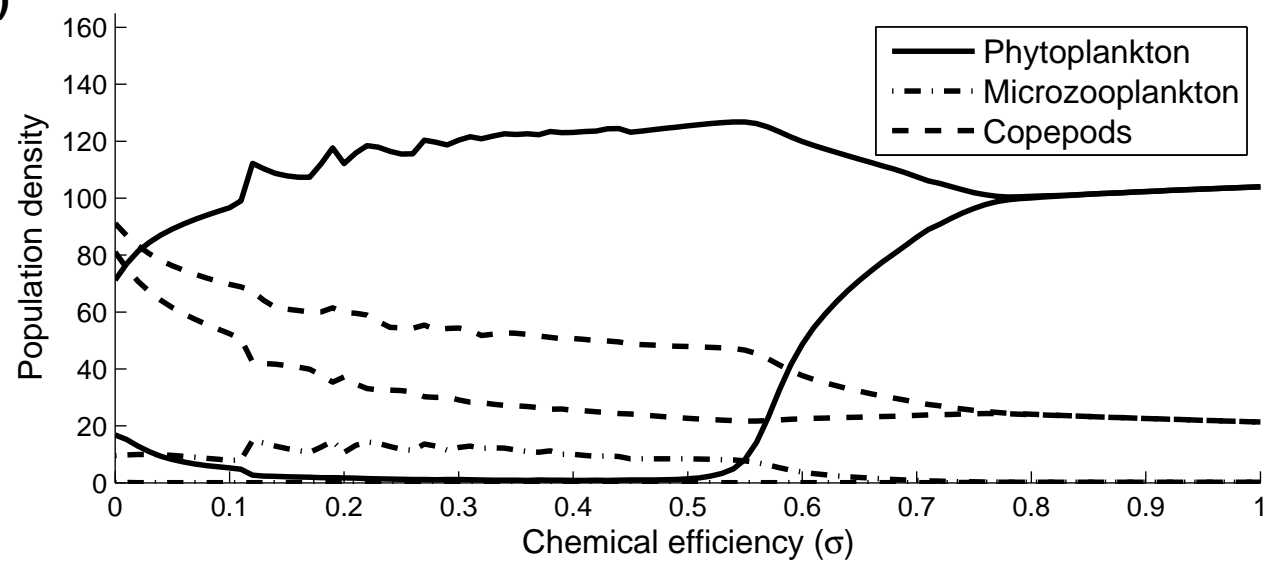

(b)

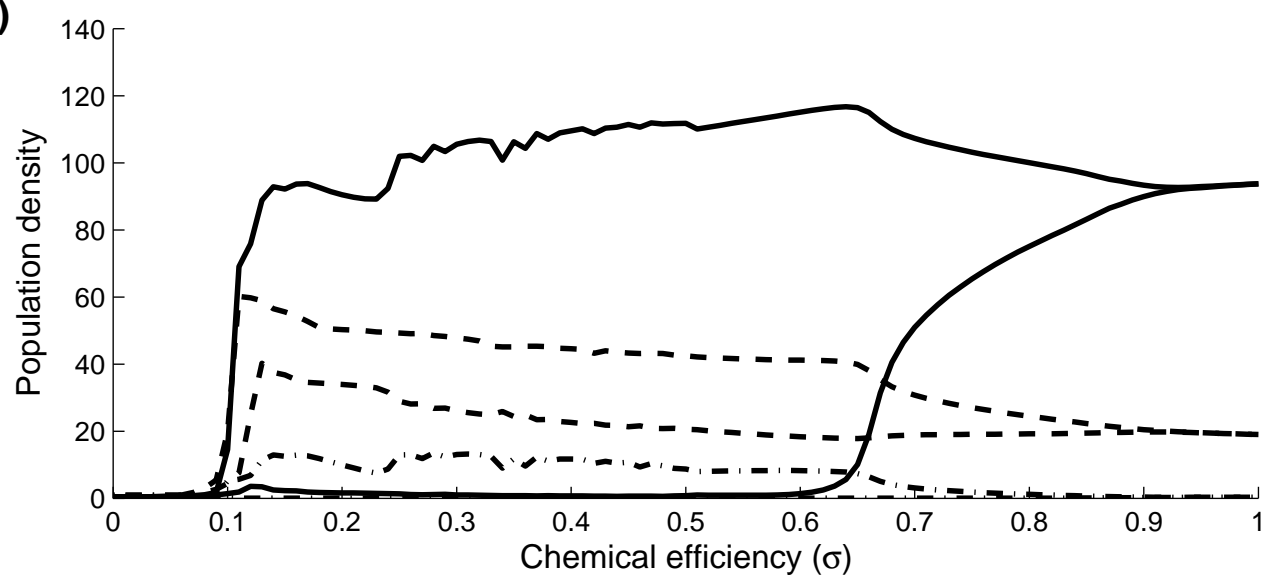

FiguRE 6. Bifurcation diagram showing the space-average plankton densities for different levels of the copepod chemical efficiency, $\sigma$, when (a) $\delta=0.01 \mathrm{~d}^{-1}$ and (b) $\delta=0.015 \mathrm{~d}^{-1}$, with all other parameters fixed at the values given in Table 1 . The diagrams show the equilibrium densities of the stable steady state or the maximum and minimum densities of the stable limit cycle. Simulations were run for 3000 days with the final 500 used to assess stability (see Appendix A). This was to produce a smoother graph.

chemical efficiency occur so rarely that the model trajectories are always settled on the attractor before another mutation occurs.

Our direct numerical simulation based on the introduction of a mutant strain reveals that for the model parameters belonging to the considered range (see Table 1), the evolutionarily stable strategy will be the one corresponding to the fully chemically informed copepods $(\sigma=1)$. Note that we consider that all other parameters (e.g. mortality rate, maximum feeding rate, etc.) describing the competing copepod strains to be the same, i.e. we assume that there is no trade-off between the efficiency $\sigma$ and other life traits. In this case, any copepod strain with a lower efficiency cannot invade the system of fully chemically informed copepods; moreover, this state is globally attracting, i.e., all random mutations of strategies starting from a smaller $\sigma$ will eventually evolve to $\sigma^{*}=1$. This conclusion is also confirmed by construction of a standard pairwise-invasibility plot technique $[8,14]$. Note that at $\sigma=1$ the gradient of the invader fitness does not vanish as it is a standard requirement of the evolutionarily singular point [8], this is due to the fact that the value $\sigma=1$ is located at the boundary of the possible range of $\sigma$. For the sake of brevity we do not present the corresponding pairwise-invasibility plot here. Thus, despite 
the fact that the fully chemically informed copepods exhibit smaller overall density $Z$, the strategy to entirely follow the vertical distribution of DMS becomes evolutionarily more advantageous.

It can be shown that the analytical condition of the evolutionarily stable strategy $\sigma^{*}$ in model (2.1-2.4), in the case of stationary dynamics, is an equilibrium point given by:

$$
\int_{0}^{H} \frac{M\left(h, \sigma^{*}\right)}{k_{2}+M\left(h, \sigma^{*}\right)} z\left(h, \sigma^{*}\right) d h>\int_{0}^{H} \frac{M\left(h, \sigma^{*}\right)}{k_{2}+M\left(h, \sigma^{*}\right)} z(h, \sigma) d h,
$$

which emphasizes the fact the fitness of the resident strain should be maximal compared to that of the other strategies [8]; here $z(h, \sigma)$ is given by Eq. 4.1. In the case of periodic oscillations, we need to maximize the time average values of fitness through the period. Numerical simulation and analytical investigation (see Appendix B) of the above condition shows that although transition to $\sigma=1$ results in a lower total amount of copepods (see Figure 6), the shape of the copepod vertical distribution $z(h, \sigma)$ becomes closer to that of $M$, thus the local consumption rate becomes higher at depths with larger $M$, thus the overall integral consumption becomes higher and condition (4.2) holds.

It is also possible to come up with a simpler (but not mathematically strict) explanation of the advantage to have $\sigma^{*}=1$ for copepods. The point is that fully chemically informed copepods can persist with lower levels of resource (i.e. the average density of microzooplankton through the column) than copepod strains with $\sigma<1$. Copepods with $\sigma=1$ feed preferentially at depths with a high density of microzooplankton and can compensate the low overall level of microzooplankton. On the contrary, randomly foraging copepods cannot invade the equilibrium state of the fully chemically informed copepods, since their survival would require larger values of $M$ than the equilibrium level of fully informed copepods. This effect is similar to the well-known result from competition theory where the most effective competitor becomes the one which can reduce the resource to the minimal level and survive at this level, which would not be possible for the other consumers of this resource [51], [41]. Finally, we should say that in this study we neglect the existence of any trade-off functions between the efficiency and the other parameters (e.g. mortality rate), which could potentially change the main prediction about $\sigma^{*}=1$ always being the evolutionarily stable strategy.

\section{Discussion}

Here we have used a 1-d reaction-diffusion food web model with an additional ordinary differential equation for copepod dynamics to investigate the effect of grazing-induced infochemicals on multitrophic plankton interactions. Our results are comparable to the main results of Lewis et al. (2012) [27], who found such interactions to have a stabilizing effect on the population dynamics and to promote the formation of phytoplankton blooms. Lewis et al. (2012) [27] used a non-spatial model where an increase of microzooplankton grazing on phytoplankton led to an increase in the microzooplankton mortality rate, assumed to be through increased predation by copepods. Here the release of grazing-induced chemicals acts to alter the distribution of copepods in the water column, so that overall predation increases in prey rich patches due to an increase of copepods migrating to these areas, rather than through an increase in the copepod predation rate. This mechanism is consistent with laboratory studies which have shown copepods follow chemical trails to track mates [23], and aggregate in layers rich with prey [e.g. 38, 52]. Additionally we have shown that foraging through the use of chemodetection provides fitness benefits to copepods and forms and evolutionarily stable strategy.

The release of grazing-induced chemicals may enhance copepod foraging in a number of ways and at different spatiotemporal scales. The distribution of phytoplankton in the oceans is highly heterogeneous [6]. However, depth profiles from the ocean have shown chemicals such as DMS to correspond well to the chlorophyll maxima [47], potentially allowing vertically migrating copepods to locate and remain within prey-rich patches. This was taken into account in our model through use of the ideal free distribution (Eq. 2.9), which allowed copepods to follow the instantaneous distribution of grazing-induced chemicals. Our results indicate that this allowed less efficient copepods (parameterized with low predation rates, $\beta$, 
or conversion efficiencies, $\epsilon$ ) to persist in a system where they would have otherwise become extinct (Figure 3). Furthermore, copepods that foraged through chemodetection were able to persist under greater predation pressure from higher trophic levels in comparison to randomly foraging copepods (Figure 2). This is a consequence of increased copepod growth rates through the conversion of more predated microzooplankton into new biomass. It should be noted that there were a few cases where copepods appeared to benefit from foraging randomly, these being the phytoplankton carrying capacity, $K$, and copepod chemical efficiencies, $\sigma$. However, in the case of the phytoplankton carrying capacity, we emphasize that we used a copepod mortality value below the range reported in Table 1 in order to produce limit cycle behaviour in the model. In the case of the copepod chemical efficiency, we demonstrated that even though copepods with low $\sigma$ values tend to higher population densities, utilizing infochemicals forms an evolutionarily stable strategy for copepods, and foraging randomly is not the best strategy to adopt. It should also be noted that use of the ideal free distribution assumes copepods have total freedom of movement and knowledge of the entire water column [12],[31]. Copepods can be modelled more realistically through use of a diffusion model with chemotaxis terms [e.g. 12], however, such an approach was beyond the scope of this paper.

Our spatial model of multitrophic interactions provides an insight regarding the potential advantage of using chemical cues by copepods. We demonstrate (Section 4) that utilizing infochemical-mediated foraging to locate microzooplankton prey is an evolutionarily stable strategy, and hence those copepods which apply this strategy obtain an advantage over randomly foraging strains. As a result, chemically informed strains of copepods will eventually outcompete those which forage randomly. Moreover, the model predicts that eventually, starting from purely random foraging behaviour $(\sigma=0)$, the strategy will finally evolve to the scenario where copepods follow the vertical distribution of chemicals with $100 \%$ efficiency $(\sigma=1)$. Interestingly, the transition to the maximal efficiency results in lower values of the overall biomass of copepods (see Figure 6). The fully informed copepod strain would minimize the level of total available resource (microzooplankton); however, it is able to compensate low food densities by foraging at depths with high abundance of microzooplankton. The other copepod strains with smaller efficiency $\sigma$ cannot survive at low resource densities and eventually die out. We should emphasize, however, that in our assumptions we neglect the possibility of the existence of possible trade-offs between the efficiency and other life history traits such as mortality, maximal growth rate, etc. Taking into account such trade-offs (e.g. the ability to precisely follow the gradient of infochemicals can require extra energy allocation and search time of copepods) could make the strategy with $100 \%$ efficiency less beneficial for copepods and the evolutionarily stable strategy would be observed for some other intermediate values of $\sigma$.

When considering randomly foraging copepods, our results are consistent with those of Rosenzweig \& MacArthur (1963) [40] who showed that an initially stable system can become destabilized upon eutrophication (higher $K$; Figure 4a). Assuming that copepods forage through chemodetection stabilizes the dynamics so that the system tended to the persistence stable steady state (Figure 1c) across the full range of $K$. These results are consistent with Lewis et al. (2012) [27], who showed infochemical-mediated predation to be stabilizing, and Morozov et al. (2011) [32], who showed vertical heterogeneity to have a stabilizing effect of the system dynamics, even at an unlimited nutrient load.

If the release of chemicals following microzooplankton grazing enhances their susceptibility to copepod predation, this may provide a 'loophole' in the microzooplankton grazing impact, leading to the formation of a phytoplankton bloom [20]. In the model presented here, phytoplankton bloom formation was possible for twenty-seven out of the thirty parameterizations given in Table 2 when copepods were assumed to forage according to the ideal free distribution, but was not possible at all when copepods foraged randomly. Furthermore, phytoplankton bloom formation was only possible when considering infochemically informed copepods in the analysis of the phytoplankton growth parameters (Figure 5). This is in agreement with laboratory and field studies that have shown the main impact of copepods on small phytoplankton species to be induced indirectly by predation on microzooplankton, releasing excessive grazing pressure from phytoplankton and, in some cases, leading to bloom formation [17,34]. The idea of an induced chemical 
defence in unicellular marine algae is controversial, as natural selection maximizes fitness at the level of the individual [24]. In the marine environment, individual cells lack fixed spatial associations and cannot, therefore, target infochemicals [26]. Consequently, the benefits of the chemical defence would be shared by not only cells of the same species but also by cells of other competing species. This is not an evolutionarily stable strategy as it gives rise to 'cheaters' who gain the benefits of the chemical defence without the metabolic costs of its production [26]. However, some chemicals proposed to function as defences, such as DMS, also serve several intracellular functions [e.g. 50]. It has therefore been proposed that the evolution of such defence mechanisms in phytoplankton has been driven by the need for metabolic processes [37]. Another possible explanation for the benefits of producing infochemicals can be spatial heterogeneity on microscales. For instance, at any given depth the concentration of DMS can vary at small scales and be higher near phytoplankton cells producing the infochemicals and lower in the vicinity of cells which do not produce them. As a result, copepods can be attracted by such microgradients of infochemicals and feed nearby. Thus infochemical producing algal colonies will be more likley to be released from microzooplankton grazing than other phytoplankton species. In our paper however, we consider a coarse spatial resolution and we do not model the mentioned effects of heterogeneity on microscales.

Chemicals released following grazing will not span the full depth of the euphotic zone, but will be transported to the surrounding area via turbulent diffusion. This can be seen in Figure 1c for our model, which shows the majority of phytoplankton to be concentrated in the upper $20 \mathrm{~m}$ of the euphotic zone, with chemicals abundant in the upper $30 \mathrm{~m}$. In reality this means that only copepods in the vicinity of an area of high biological activity will be able to make use of such chemical information, with copepods outside this area having to forage randomly or make use of other prey related cues. Woodson et al. (2007) [56] suggested a copepod cue hierarchy, employed by copepods to narrow their search for prey. They estimated that, in a $25 \mathrm{~m}$ water column, the majority of phytoplankton biomass is concentrated in $4-16 \%$ of the habitat, with chemical exudates increasing this area to $4-20 \%$ and other prey related cues, such as velocity gradients, to 15-25\% [56]. The model presented here does not account for a 'two-phase' strategy of copepods that varies with depth, however, the formulation given by Eq. 4.1 does allow us to vary the amount by which copepods forage randomly and through chemodetection by allowing us to adjust the efficiency with which the copepod distribution matches that of chemicals. It was shown that increasing the chemical following efficiency of randomly foraging copepods by just $2 \%$ allowed them to persist with a mortality rate that would have otherwise driven them to extinction. A 79-93\% chemical following efficiency was required for system stabilization and phytoplankton bloom formation to take place. Such a high chemical following efficiency is unlikely in nature [56], but the effects may be possible if the utilization of infochemicals is combined with other cues and search strategies not accounted for within our model. Furthermore, by considering the chemical following efficiency of a competiting copepod population, we were able to demonstrate that using chemodectection to locate microzooplankton prey forms an evolutionarily stable strategy for copepods in this system.

In this paper we have used DMS as an example infochemical that has been well quantified in other modelling studies. DMS has been shown to elicit a behavioural foraging response in many marine organisms, including the copepod T. longicornis, suggesting that copepods may use this chemical information when searching for microzooplankton prey [49]. As the production of DMS is rapidly accelerated following microzooplankton grazing on phytoplankton $[1,55]$, DMS is a potential candidate for the mediation of multitrophic interactions in the plankton [48]. A recent laboratory study found no differences in the pooled time budget of individual copepods allocated to slow swimming (associated with foraging) when subject to high or low DMS treatments [3], however, these experiments can be considered to examine the behaviour of individual copepods once in a prey patch. Further experiments are needed to assess the effect of DMS at the population level on a larger spatial scale. Regardless, infochemicals are ubiquitous in the marine environment and play important roles in the structure and functioning of marine food webs [18]. The model presented here gives an insight into the possible function of infochemicals in a planktonic food web, and presents a potential mechanism for system stabilization and bloom formation. 


\section{Appendix A}

Here we describe the method used to carry out the bifurcation analyses. The pseudo code for oneparameter bifurcations is given by:

1. Define fixed parameter values.

2. Create a for loop to run through increasing values of the bifurcation parameter.

3. For each value of the bifurcation parameter:

(a) Run the simulation for 2000 time steps to get rid of transients.

(b) Run for a further 100 time steps and record the mean (depth-averaged) densities in vectors PP, MM \& ZZ.

(c) Record the mean densities at the end of the simulation as EP, EM \& EZ.

(d) i. If the difference between the highest and lowest value in each vector (PP, MM, ZZ) is less than 0.03 assume an equilibrium has been reached and record EP, EM \& EZ in a solution vector.

ii. If the difference between the highest and lowest value in each vector (PP, MM, ZZ) is greater than 0.03 assume a stable limit cycle has been reached and record the maximum and minimum values in the solution vector.

4. Plot the values in the solution vector against the bifurcation parameter.

A similar method is used for the two-parameter bifurcation maps. In this case a for loop is used for each bifurcation parameter and the if statement tests for copepod persistence / bloom formation as well as stability, where copepod persistence is assumed if $\bar{Z} \geq 0.1 \mu \mathrm{g} \mathrm{C} \mathrm{l}^{-1}$ and phytoplankton bloom formation is assumed if an equilibrium is reached where $P_{\text {surf }} \geq 50 \mu \mathrm{g} \mathrm{C}^{-1}$.

\section{Appendix B}

Here we show (under some assumptions) why condition (4.2) of the evolutionarily stable strategy is satisfied for the fully chemically informed zooplankton $\left(\sigma^{*}=1\right)$

The proof will require the following assumption

$$
\frac{C(h)}{\bar{C}} \approx \frac{M(h)}{\bar{M}},
$$

in other words we consider that the relative distribution of DMS in the column can be replaced by that of microzooplankton. Note that although this assumption is not fully true throughout the column (e.g. at the surface level, see Fig.1a), numerical simulation shows that deviation from (B2) at all other depths across the column is very small.

In the case (B1) holds, we can re-write condition (4.2) as

$$
\Delta=\int_{0}^{H} \frac{M\left(h, \sigma^{*}\right)}{k_{2}+M\left(h, \sigma^{*}\right)} \frac{M\left(h, \sigma^{*}\right)}{\overline{M\left(h, \sigma^{*}\right)}} d h-\int_{0}^{H} \frac{M\left(h, \sigma^{*}\right)}{k_{2}+M\left(h, \sigma^{*}\right)}\left[1-\sigma+\sigma \frac{M\left(h, \sigma^{*}\right)}{\overline{M\left(h, \sigma^{*}\right)}}\right] d h,
$$

since the vertical distribution of invader stain of copepods (when rare), corresponding to efficiency $\sigma$ is given by

$$
z(h)=1-\sigma+\sigma \frac{M(h)}{\bar{M}},
$$

where the optimal value of chemical efficiency is given by $\sigma^{*}=1$.

We re-arrange the expression for $\Delta$ and obtain

$$
\Delta=(1-\sigma) \int_{0}^{H} \frac{M\left(h, \sigma^{*}\right)}{k_{2}+M\left(h, \sigma^{*}\right)}\left[\frac{M\left(h, \sigma^{*}\right)}{\overline{M\left(h, \sigma^{*}\right)}}-1\right] d h .
$$


We further have

$$
\Delta=(1-\sigma)\left(\int_{\Omega_{1}} \frac{M\left(h, \sigma^{*}\right)}{k_{2}+M\left(h, \sigma^{*}\right)}\left[\frac{M\left(h, \sigma^{*}\right)}{\overline{M\left(h, \sigma^{*}\right)}}-1\right] d h+\int_{\Omega_{2}} \frac{M\left(h, \sigma^{*}\right)}{k_{2}+M\left(h, \sigma^{*}\right)}\left[\frac{M\left(h, \sigma^{*}\right)}{\overline{M\left(h, \sigma^{*}\right)}}-1\right] d h\right),
$$

where the domains $\Omega_{1}$ and $\Omega_{2}$ comprise all intervals of the positive and negative value of the integrand, respectively. It is easy to see that

$$
\int_{\Omega_{1}} \frac{M\left(h, \sigma^{*}\right)}{k_{2}+M\left(h, \sigma^{*}\right)}\left[\frac{M\left(h, \sigma^{*}\right)}{\overline{M\left(h, \sigma^{*}\right)}}-1\right] d h>\int_{\Omega_{1}} \frac{\overline{M\left(h, \sigma^{*}\right)}}{k_{2}+\overline{M\left(h, \sigma^{*}\right)}}\left[\frac{M\left(h, \sigma^{*}\right)}{\overline{M\left(h, \sigma^{*}\right)}}-1\right] d h>0,
$$

and

$$
\int_{\Omega_{2}} \frac{M\left(h, \sigma^{*}\right)}{k_{2}+M\left(h, \sigma^{*}\right)}\left[\frac{M\left(h, \sigma^{*}\right)}{\overline{M\left(h, \sigma^{*}\right)}}-1\right] d h>\int_{\Omega_{2}} \frac{\overline{M\left(h, \sigma^{*}\right)}}{k_{2}+\overline{M\left(h, \sigma^{*}\right)}}\left[\frac{M\left(h, \sigma^{*}\right)}{\overline{M\left(h, \sigma^{*}\right)}}-1\right] d h<0,
$$

By combining (B.5), (B.6) and (B.7) we obtain

$$
\Delta>(1-\sigma)\left(\int_{\Omega_{1}} \frac{\overline{M\left(h, \sigma^{*}\right)}}{k_{2}+\overline{M\left(h, \sigma^{*}\right)}}\left[\frac{M\left(h, \sigma^{*}\right)}{\overline{M\left(h, \sigma^{*}\right)}}-1\right] d h-\int_{\Omega_{2}} \frac{\overline{M\left(h, \sigma^{*}\right)}}{k_{2}+\overline{M\left(h, \sigma^{*}\right)}}\left[\frac{M\left(h, \sigma^{*}\right)}{\overline{M\left(h, \sigma^{*}\right)}}-1\right] d h\right)=0
$$

It is important to stress that the latter inequality is a strong inequality, i.e. $\Delta>0$, and this would signify that condition (B2) holds (which is equivalent to condition (4.2)) and the fitness of a mutant will be always smaller than that of the resident with $\sigma^{*}=1$. Thus $\sigma^{*}=1$ is the evolutionarily stable strategy.

Note that in a similar way one can prove that

$$
\int_{0}^{H} \frac{M\left(h, \sigma_{1}\right)}{k_{2}+M\left(h, \sigma_{1}\right)} z\left(h, \sigma_{1}\right) d h>\int_{0}^{H} \frac{M\left(h, \sigma_{1}\right)}{k_{2}+M\left(h, \sigma_{1}\right)} z\left(h, \sigma_{2}\right) d h,
$$

for $\sigma_{1}>\sigma_{2}$ in other words, the strategy $\sigma^{*}=1$ is a convergence stable (attracting) strategy: all mutations starting from $\sigma<1$ will eventually evolve to $\sigma^{*}=1$.

Acknowledgements. This work was funded by a grant from the UK Natural Environment Research Council (NERC; NE/H009485/1).

\section{References}

[1] S. D. Archer, C. E. Stelfox-Widdicombe, P. H. Burkill, G. Malin. A dilution approach to quantify the production of dissolved dimethylsulphoniopropionate and dimethylsulphide due to microzooplankton herbivory. Aquat. Microb. Ecol., 23 (2001), 131-145.

[2] A. Beckmann, I. Hense. Beneath the surface: characteristics of oceanic ecosystems under weak mixing conditions - a theoretical investigation. Prog. Oceanogr., 75 (2007), 771-796.

[3] M. N. Breckels, N. W. F. Bode, E. A. Codling, M. Steinke. The effect of grazing-mediated DMS production on the behaviour of the copepod Calanus helgolandicus. Mar. Drugs, 11 (2013), 2486-2500.

[4] R. J. Charlson, J. E. Lovelock, M. O. Andreae, S. G. Warren. Oceanic phytoplankton, atmospheric sulphur, cloud albedo and climate. Nature, 326 (1987), 655-661.

[5] J. Chattopadhyay, R. R. Sarkar, S. Mandal. Toxin producing plankton may act as a biological control for planktonic blooms-field study and mathematical modelling. J. Theor. Biol., 215 (2002), 333-344.

[6] T. J. Cowles, R. A. Desiderio, M. E. Carr. Small scale planktonic structure: persistence and trophic consequences. J. Oceanogr., 11 (1998), 4-9.

[7] G. B. Cunningham, V. Strauss, P. G. Ryan. African penguins (Spheniscus demersus) can detect dimethyl sulphide, a prey related cue. J. Exp. Biol., 211 (2008), 3123-3127.

[8] U. Dieckmann. Adaptive dynamics of pathogen-host interactions. In: Dieckmann, U, Metz, JAJ, Sabelis, M.W., Sigmund, K. (Eds.), Adaptive Dynamics of Infectious Diseases:In Pursuit of Virulence Management, Cambridge University Press, (2002), pp. 39-59. 
[9] C. A. Edwards, H. P. Batchelder, T. M. Powell. Modeling microzooplankton and macrozooplankton dynamics within a coastal upwelling system. J. Plankton Res., 22 (2000), 1619-1648.

[10] C. A. Edwards, T. A. Powell, H. P. Batchelder. The stability of an NPZ model subject to realistic levels of vertical mixing. J. Mar. Res., 58 (2000), 37-60.

[11] A. M. Edwards, J. Brindley. Zooplankton mortality and the dynamical behaviour of plankton population models. Bull. Math. Biol., 61 (1999), 303-339.

[12] K. D. Farnsworth, J. A. Beecham. How do grazers achieve their distribution? A continuum of models from random diffusion to the ideal free distribution using biased random walks. Am. Nat., 153 (1999), 509-526.

[13] A. Gabric, N. Murray, L. Stone, M. Kohl. Modelling the production of dimethylsulfide during a phytoplankton bloom. J. Geophys. Res., 98 (1993), 22805-22816.

[14] S.A.H., Geritz, E. Kisdi, G. Meszena, J.A.J. Metz, Evolutionarily singular strategies and the adaptive growth and branching of the evolutionary tree. Evol. Ecol., 12, (1998), 35-57.

[15] C. W. Gill, S. A. Poulet. Responses of copepods to dissolved free amino acids. Mar. Ecol. Prog. Ser., 43 (1988), $269-276$.

[16] J. Giske, R. Rosland, J. Berntsen, Ø. Fiksen. Ideal free distribution of copepods under predation risk. Ecol. Model., 95 (1997), 45-59.

[17] F. C. Hansen, M. Reckermann, W. C. M. Klein Breteler. Phaeocystis blooming enhanced by copepod predation on protozoa: evidence from incubation experiments. Mar. Ecol. Prog. Ser., 102 (1993), 51-57.

[18] M. E. Hay. Marine chemical ecology: chemical signals and cues structure marine populations, communities and ecosystems. Annu. Rev. Mar. Sci., 1 (2009), 193-212.

[19] C. S. Holling. The components of predation as revealed by a study of small mammal predation on the European pine sawfly. Can. Entomol., 91 (1959), 293-320.

[20] X. Irigoien, K. J. Flynn, R. P. Harris. Plankton blooms: a 'loophole' in microzooplankton grazing impact? J. Plankton Res., 27 (2005), 313-321.

[21] A. Kharab, R. B. Guenther. An Introduction to Numerical Methods: A MATLAB Approach. Third edition. CRC Press, Boca Raton, 2012.

[22] T. Kiørboe. A Mechanistic Approach to Plankton Ecology. Princeton University Press, NJ, 2008.

[23] T. Kiørboe, E. Bagøien, U. H. Thygesen. Blind dating-mate finding in planktonic copepods. II. the pheromone cloud of Pseudocalanus elongatus. Mar. Ecol. Prog. Ser., 300 (2005), 117-128.

[24] C. J. Krebs. Ecology. Sixth edition. Pearson, San Francisco, 2009.

[25] W. Lampert. Vertical distribution of zooplankton: density dependence and evidence for an ideal free distribution with costs. BMC Biol., 3 (2005), 10.

[26] W. M. Lewis. Evolutionary interpretations of allelochemical interactions in phytoplankton algae. Am. Nat., 127 (1986), $184-194$.

[27] N. D. Lewis, M. N. Breckels, S. D. Archer, A. Morozov, J. W. Pitchford, M. Steinke, E. A. Codling. Grazing-induced production of DMS can stabilize food-web dynamics and promote the formation of phytoplankton blooms in a multitrophic plankton model. Biogeochemistry, 110 (2012), 303-313.

[28] N. D. Lewis, M. N. Breckels, M. Steinke, E. A. Codling. Role of infochemical mediated zooplankton grazing in a phytoplankton competition model. Ecol. Complex., (2012), http://dx.doi.org/10.1016/j.ecocom.2012.10.003.

[29] MATLAB. The Language of Technical Computing, version 7.8. Mathworks, Natick, MA.

[30] D. J. S. Montagnes, J. A. Berges, P. J. Harrison, F. J. R. Taylor. Estimating carbon, nitrogen, protein, and chlorophyll a from volume in marine phytoplankton. Limnol. Oceanogr., 39 (1994), 1044-1060.

[31] A. Morozov, E. Arashkevich, Towards a correct description of zooplankton feeding in models: Taking into account food-mediated unsynchronized vertical migration. J. Theor. Biol., 262 (2010), 346-360.

[32] A. Morozov, E. Arashkevich, A. Nikishina, K. Solovyev. Nutrient-rich plankton community stabilized via predator-prey interactions: revisiting the role of vertical heterogeneity. Math. Med. Biol., 28 (2011), 185-215.

[33] J. C. Nejstgaard, U. Båmstedt, E. Bagøien, P. T. Solberg. Algal constraints on copepod grazing. Growth state, toxicity, cell size, and season as regulating factors. ICES J. Mar. Sci., 52 (1995), 347-357.

[34] J. C. Nejstgaard, I. Gismervik, P. T. Solberg. Feeding and reproduction by Calanus finmarchicus, and microzooplankton grazing during mesocosm blooms of diatoms and the coccolithophore Emiliania huxleyi. Mar. Ecol. Prog. Ser., 147 (1997), 197-217.

[35] G. A. Nevitt, R. R. Veit, P. Kareiva. Dimethyl sulphide as a foraging cue for Antarctic Procellariiform seabirds. Nature, 376 (1995), 680-682.

[36] G. Pohnert, O. Lumineau, A. Cueff, S. Adolph, C. Cordevant, M. Lange, S. Poulet. Are volatile unsaturated aldehydes from diatoms the main line of chemical defence against copepods?. Mar. Ecol. Prog. Ser., 245 (2002), 33-35.

[37] G. Pohnert, M. Steinke, R. Tollrian. Chemical cues, defense metabolites and the shaping of pelagic interspecific interactions. Trends Ecol. Evol., 22 (2007), 198-204.

[38] S. A. Poulet, G. Ouellet. The role of amino acids in the chemosensory swarming and feeding of marine copepods. J. Plankton Res., 4 (1982), 341-361.

[39] M. L. Rosenzweig. Paradox of enrichment: destabilization of exploitation ecosystems in ecological time. Science, 171 (1971), 385-387.

[40] M. L. Rosenzweig, R. H. MacArthur. Graphical representation and stability conditions of predator-prey interactions. Am. Nat., 97 (1963), 209-223.

[41] A. B. Ryabov, B Blasius. A graphical theory of competition on spatial resource gradients. Ecol. Lett 14 (2011), 220-228 
[42] A. B. Ryabov. Phytoplankton competition in deep biomass maximum. Theor. Ecol., 5 (2012), 373-385.

[43] E. S. Saltzman, D. B. King, K. Holmen, C. Leck. Experimental determination of the diffusion coefficient of dimethylsulfide in water. J. Goephys. Res., 98 (1993), 16481-16486.

[44] B. A. Shaw, R. J. Andersen, P.J. Harrisen. Feeding deterrence properties of apo-fucoxanthinoids from marine diatoms. I. Chemical structures of apo-fucoxanthinoids produced by Phaeodactylum tricornutum. Mar. Biol., 124 (1995), 467-472.

[45] B. A. Shaw, P. J. Harrison, R. J. Andersen. Feeding deterrence properties of apo-fucoxanthinoids from marine diatoms. II. Physiology of production of apo-fucoxanthinoids by the marine diatoms Phaeodactylum tricornutum and Thalassiosira pseudonana, and their feeding deterrence effects on the copepod Tigriopus californicus. Mar. Biol., 124 (1995), 473-481.

[46] J. Stefels, M. Steinke, S. Turner, G. Malin, S. Belviso. Environmental constraints on the production and removal of the climatically active gas dimethylsulphide (DMS) and implications for ecosystem modelling. Biogeochemistry, 83 (2007), $245-275$.

[47] M. Steinke, G. Malin, S. D. Archer, P. H. Burkill, P. S. Liss. DMS production in a coccolithophorid bloom: evidence for the importance of dinoflagellate DMSP lyases. Aquat. Microb. Ecol., 26 (2002), 259-270.

[48] M. Steinke, G. Malin, P. S. Liss. Trophic interactions in the sea: an ecological role for climate relevant volatiles? J. Phycol., 38 (2002), 630-638.

[49] M. Steinke, J. Stefels, E. Stamhuis. Dimethyl sulfide triggers search behaviour in copepods. Limnol. Oceanogr., 51 (2006), 1925-1930.

[50] W. Sunda, D. J. Kieber, R. P. Kiene, S. Huntsman. An antioxidant function for DMS and DMSP in marine algae. Nature, 418 (2002), 317-320.

[51] D. Tilman. Resource Competition and Community Structure. Princeton University Press, Princeton, NJ.

[52] P. Tiselius. Behaviour of Acartia tonsa in patchy food environments. Limnol. Oceanogr., 37 (1992), 1640-1651.

[53] J. T. Turner, P. A. Tester. Toxic marine phytoplankton, zooplankton grazers, and pelagic food webs. Limnol. Oceanogr., 42 (1997), 1203-1214.

[54] A. W. Visser, T. Kiørboe. Plankton motility patterns and encounter rates. Oecologia, 148 (2006), 538-546.

[55] G. V. Wolfe, M. Steinke. Grazing-activated production of dimethyl sulfide (DMS) by two clones of Emiliania huxleyi. Limnol. Oceanogr., 41 (1996), 1151-1160.

[56] C. B. Woodson, D. R. Webster, M. J. Weissburg, J. Yen. Cue hierarchy and foraging in calanoid copepods: ecological implications of oceanographic structure. Mar. Ecol. Prog. Ser., 330 (2007), 163-177.

[57] H. Yamazaki, K. D. Squires. Comparison of oceanic turbulence and copepod swimming. Mar. Ecol. Prog. Ser., 144 (1996), 299-301.

[58] J. Yen, K. D. Rasberry, D. R. Webster. Quantifying copepod kinematics in a laboratory apparatus. J. Mar. Syst., 69 (2008), 283-294. 